\title{
Impact of early hypothalamic-pituitary-gonadal axis maturation on prostate cancer: cross-sectional analysis of a Veterans affairs cohort
}

\author{
Rimaz M. Khadir ${ }^{1}$, Rashid K. Sayyid ${ }^{2,3}$, Brian Matthews ${ }^{2}$, Sherita A. King ${ }^{2,3}$, Martha K. Terris ${ }^{2,3}$ \\ ${ }^{1}$ Medical College of Georgia, Augusta, GA, USA; ${ }^{2}$ Charlie Norwood VA Medical Center, Augusta, GA, USA; ${ }^{3}$ Department of Surgery, Section of \\ Urology, Medical College of Georgia, Augusta University, Augusta, GA, USA \\ Contributions: (I) Conception and design: MK Terris, SA King; (II) Administrative support: B Matthews; (III) Provision of study materials or patients: \\ MK Terris, SA King, B Matthews; (IV) Collection and assembly of data: MK Terris, SA King, B Matthews; (V) Data analysis and interpretation: RM \\ Khadir, RK Sayyid, MK Terris; (VI) Manuscript writing: All authors; (VII) Final approval of manuscript: All authors. \\ Correspondence to: Martha K. Terris, MD, FACS. Witherington Distinguished Professor and Chair in Urology, Department of Surgery, Section of \\ Urology, Augusta University, 1120 15th Street, BA-8414, Augusta, GA 30912, USA. Email: mterris@augusta.edu.
}

Background: It has been hypothesized that earlier onset of puberty, and thus a more prolonged exposure
to high androgen levels, increases risk of prostate cancer development. Our objective was to determine
whether earlier age of first shave and height, as surrogates of pubertal onset, were associated with risk of
prostate cancer diagnosis. Methods: A prospectively collected outcomes registry of patients presenting for a prostate biopsy at the Charlie Norwood Veterans Affair Medical Center in Augusta, GA between July 1995 and June 2016 was utilized. The associations between age of first shave and height, each, and risks of a positive prostate biopsy, high grade cancer, and high volume disease were evaluated using univariable and multivariable logistic regression analysis, controlling for baseline patient demographic and oncologic characteristics.

Results: Our cohort included 2,456 patients. Biopsies were positive in 1,257 (51.2\%) patients, of whom 293 (23.3\%) and 407 (32.4\%) had high grade and volume disease, respectively. Median age of first shave was 17.0 years (interquartile range 16.0-19.0) and height was $177.7 \mathrm{~cm}(172.8-182.9)$. On multivariable analysis, later of age of first shave was significantly associated with increased odds of a positive prostate biopsy (odds ratio for $>18$ versus $<16$ years: $5.34, \mathrm{P}=0.02$ ) and taller patients had significantly increased odds of high grade cancer (odds ratio for $175-180$ versus $<175 \mathrm{~cm}$ : 7.46, $\mathrm{P}=0.037$ ).

Conclusions: Amongst patients presenting for a prostate biopsy, those with a later age of first shave and taller height have an increased risk of a positive prostate biopsy and high grade prostate cancer, respectively.

Keywords: Prostatic neoplasms; biopsy; puberty; testosterone

Submitted May 13, 2021. Accepted for publication Jun 30, 2021.

doi: $10.21037 /$ tau-21-433

View this article at: https://dx.doi.org/10.21037/tau-21-433

\section{Introduction}

Given the high prevalence of prostate cancer (PCa) in men (1), there has been a long-standing interest in the underlying pathogenesis of this malignancy. This disease process likely begins early in adulthood with autopsy studies demonstrating the presence of PCa precursor lesions in prostates of men in their twenties $(2,3)$. As the prostate gland is highly sensitive to its hormonal milieu during puberty (2,3), variations in androgen levels during this period may potentially impact risk of PCa pathogenesis.

Maturation of the hypothalamic-pituitary-gonadal axis at time of puberty is associated with a surge of androgen levels (4). It has been hypothesized that an earlier androgen surge, and thus a more prolonged exposure to higher 
androgen levels, may be associated with an increased risk of PCa development (5). While it may be difficult to discern the exact timing of puberty, it has been shown that earlier age of puberty is associated with earlier closure of the epiphyseal plate (6), and thus shorter adult height, and that shaving is one of the male pubertal milestones (7). We thus aimed to investigate the association between age of first shave and height, surrogates for age of puberty, and risk of PCa in men presenting for a prostate biopsy. We present the following article in accordance with the STROBE reporting checklist (available at https://dx.doi.org/10.21037/tau-21-433).

\section{Methods}

\section{Study design and participants}

We utilized a prospectively collected outcomes registry of 2,480 patients presenting for a prostate biopsy at the Charlie Norwood Veterans Affairs (VA) Medical Center in Augusta, GA between July 1995 and June 2016. Patients missing information regarding results of prostate biopsy were excluded from our cohort. If patients underwent more than one biopsy, results of the first biopsy were included and they were subsequently censored to minimize confounding secondary to sampling biases. Appropriate institutional review board ethics approval was obtained at time of registry creation, with a yearly review process ensuring compliance with institutional reporting/ethics standards.

\section{Study objectives}

Our primary study objective was to evaluate the association between patient age of first shave and adult height, each, and presence of prostate adenocarcinoma on prostate biopsy (i.e., a positive prostate biopsy). Secondary objectives included evaluating the association between these two variables (i.e., age of first shave and adult height) and presence of high grade cancer on biopsy [defined by a Gleason Score (GS) of 8 or worse], high volume of cancer on biopsy (defined by $50 \%$ or more positive cores), and prostate volume as per transrectal ultrasound.

\section{Study variables}

All baseline patient characteristics were recorded at time of prostate biopsy. The two primary study variables were age of first shave (patient-reported) and patient adult height (recorded by a clinic nurse). Available baseline patient characteristics included: age, body mass index (BMI), race (Caucasian, African American, other), family history of PCa (yes versus no), prostate-specific antigen (PSA) level, percent free PSA level, clinical stage, prostate volume as per transrectal ultrasound, presence of cancer on biopsy (yes versus no), GS, and number of biopsy cores positive and sampled. Percentage of positive cores was derived from number of positive and sampled biopsy cores.

\section{Statistical analysis}

Continuous variables were described using medians and interquartile ranges (IQR), whereas frequencies and proportions were used for categorical variables. Continuous variables were compared using the Student's $t$-test, while the chi-square test was used for categorical variables. Correlation between variables was assessed using the Pearson correlation coefficient. The associations between the two primary study variables and presence of $\mathrm{PCa}$ on biopsy, high grade cancer, and high volume cancer (binary dependent variables) were evaluated using univariable and multivariable logistic regression analyses, whereas gamma regression analysis was used to evaluate the association with prostate volume (continuous dependent variable). Age of first shave and height were operationalized as categorical variables with cutoffs selected by an author consensus to ensure relatively balanced distributions of study patients in each of the age/height category groups. Age of first shave was operationalized as follows: $<16,16-18$, and $>18$ years, whereas height was categorized as $<175,175-180$, and $>180 \mathrm{~cm}$. All of the remaining study variables, operationalized as categorical variables, were included in both the univariable and multivariable models in order to minimize any potential sources of confounding. Potential interactions between patient race and each of age of first shave and height were evaluated on a univariable level. The variance inflation factor test was used to evaluate variable collinearity. Sensitivity analyses to evaluate the effect of missing primary variables (age of first shave and height) by including only patients with all available data was performed to evaluate whether significant findings remained consistent between the full study cohort and the sub cohort with no missing data. Statistical significance was set at a two-sided $\mathrm{P}$ value of 0.05 . Analyses were performed using $\mathrm{R}$ version 3.6.1 (The R Foundation for Statistical Computing, Vienna, Austria). 


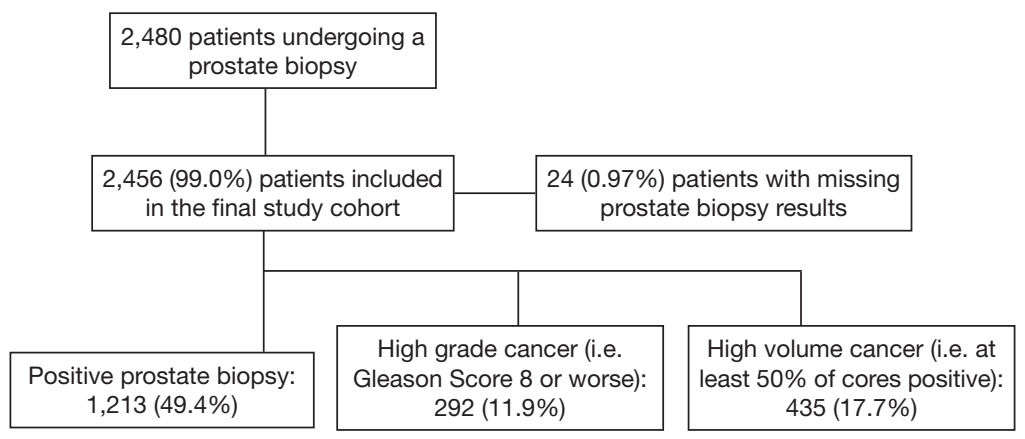

Figure 1 Study flow chart.

\section{Ethics statement}

The trial was conducted in accordance with the Declaration of Helsinki (as revised in 2013). The study was approved by the institutional review board of Augusta University (IRB No. 611094) and informed consent was taken from all individual participants.

\section{Results}

Our study cohort included 2,456 patients undergoing a prostate biopsy (Figure 1). Baseline patient characteristics are found in Table 1. Median patient age was 61.1 years (IQR 57.1-66.2) and 1,199 (48.8\%) were African American. Median PSA at time of biopsy was $5.6 \mathrm{ng} / \mathrm{mL}$ (IQR 4.78.0), with median \% free PSA of $14.7 \%$ (IQR 10.0-18.8). Median prostate volume was $38.3 \mathrm{cc}$ (IQR 29.1-54). Of the 2,456 initial biopsies performed, 1,257 (1.2\%) were positive for malignancy. Of patients diagnosed with $\mathrm{PCa}$, $293(23.3 \%)$ had high grade disease (i.e., GS 8 or worse) and 407 (32.4\%) had high volume disease (i.e., $\geq 50 \%$ cores sampled were positive for malignancy). Sextant cores were obtained in $340(13.8 \%)$, eight cores in $788(32.0 \%)$, and twelve cores in 1328 (54.1\%) patients. There were no significant differences in baseline patient characteristics of patients undergoing twelve versus non-twelve core biopsies (Table S1).

Median age of first shave was 17.0 years (IQR 16.0-19.0) and median patient height was $177.7 \mathrm{~cm}$ (IQR 172.8-182.9). Later age of first shave was associated with increased adult height (Pearson's correlation coefficient, $\mathrm{R}^{2}=0.70$ ).

On univariable logistic regression analyses, patients with later age of first shave had significantly higher odds of a positive prostate biopsy [odds ratio (OR) for 16-18 years versus $<16$ years: $1.50, \mathrm{P}=0.006$, Table S2]. There was no significant association with odds of high grade or high volume PCa on biopsy (Tables S3,S4). On multivariable analysis, later age of first shave was still significantly associated with increased odds of a positive prostate biopsy (OR for $>18$ years versus $<16$ years: $5.34, \mathrm{P}=0.02$, Table 2 ). There was an increased incidence of high volume cancer in patients with later age of first shave (OR for $16-18$ versus $<16$ years: 11.55 , $\mathrm{P}=0.057$, Table 2). No interaction was seen between patient race and age of first shave with regards to associated risk of any, high grade or high volume PCa (Tables S2-S4).

On univariable logistic regression analyses, patient height was not associated with presence of $\mathrm{PCa}$ on prostate biopsy (Tables S2-S4). On multivariable analyses, taller patients had significantly increased odds of high grade cancer on

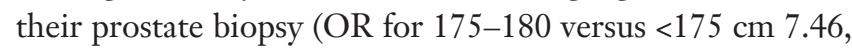
$\mathrm{P}=0.037$, Table 2). No interaction was seen between patient race and adult height with regards to associated risk of any, high grade or high volume PCa (Tables S2-S4).

Patient age of first shave was not associated with prostate volume on ultrasound on both univariable and multivariable gamma regression analyses ( $>>0.05$, Tables $\mathrm{S} 5$ and $\mathrm{S} 6$ ). Taller patients had larger prostates (coefficient for $>180 \mathrm{~cm}$ versus $<175 \mathrm{~cm} 1.11, \mathrm{P}<0.001)$ on univariable analysis (Table S5). This association was no longer significant on multivariable analysis (Table S6).

Sensitivity analyses in the subcohort of patients $(n=1,176)$ with no missing age of first shave or height data demonstrated consistent results with older patients having increased odds of a positive prostate biopsy (OR for $>18$ versus $<16$ years: 5.36 , $\mathrm{P}=0.03$ ) and taller patients having increased odds of high grade cancer on their prostate biopsy (OR for 175-180 versus 
Table 1 Baseline patient characteristics $(n=2,456)$

\begin{tabular}{|c|c|}
\hline Characteristics & Value \\
\hline Age in years, median (IQR) & $61.1(57.1-66.2)$ \\
\hline \multicolumn{2}{|l|}{ Race, n (\%) } \\
\hline African American & $1,199(48.8)$ \\
\hline Caucasian & $1,196(48.7)$ \\
\hline Other & $61(2.5)$ \\
\hline $\mathrm{BMI}$ in kg/m², median (IQR) & $28.6(25.7-32.1)$ \\
\hline Height in cm, median (IQR) & $177.7(172.8-182.9)$ \\
\hline \multicolumn{2}{|l|}{ Height in cm, n (\%) } \\
\hline$<175 \mathrm{~cm}$ & $752(30.6)$ \\
\hline $175-180 \mathrm{~cm}$ & $634(25.8)$ \\
\hline$>180 \mathrm{~cm}$ & $1,060(43.2)$ \\
\hline Not available & $10(0.41)$ \\
\hline Age of first shaving in years, median (IQR) & $17.0(16.0-19.0)$ \\
\hline \multicolumn{2}{|l|}{ Age of first shaving in years, $\mathrm{n}(\%)$} \\
\hline$<16$ years & $239(9.73)$ \\
\hline $16-18$ years & $613(25.0)$ \\
\hline$>18$ years & $310(12.6)$ \\
\hline Not available & $1,294(52.7)$ \\
\hline PSA in ng/mL, median (IQR) & $5.6(4.7-8.0)$ \\
\hline \% Free PSA, median (IQR) & $14.7(10.0-18.8)$ \\
\hline \multicolumn{2}{|l|}{ Clinical T Stage, n (\%) } \\
\hline$\leq \mathrm{T} 1 \mathrm{c}$ & $1,670(68.0)$ \\
\hline $\mathrm{T} 2$ & $737(30.0)$ \\
\hline$\geq \mathrm{T} 3$ & $49(2.0)$ \\
\hline Prostate volume in cc, median (IQR) & $38.3(29.1-54.1)$ \\
\hline Positive prostate biopsies, n (\%) & $1,257(51.2)$ \\
\hline \multicolumn{2}{|l|}{ Gleason Score, n (\%) } \\
\hline$\leq 6(3+3)$ & $488(38.8)$ \\
\hline $7(3+4)$ & $266(21.2)$ \\
\hline $7(4+3)$ & $210(16.7)$ \\
\hline $8(4+4)$ & $202(16.1)$ \\
\hline$\geq 9$ & $91(7.2$ \\
\hline Percent positive cores, median (IQR) & $18.5(4.3-28.8)$ \\
\hline
\end{tabular}

$\mathrm{BMI}$, body mass index; IQR, interquartile range; PSA, prostate specific antigen.
$<175$ cm: 7.41, $\mathrm{P}=0.038$, Tables S7-S13).

\section{Discussion}

Our results demonstrate that indicators of somatic/pubertal development are associated with risk of $\mathrm{PCa}$ in patients presenting for a prostate biopsy. Namely, patients who start shaving after 18 years of age have a five-fold greater risk of a positive prostate biopsy compared to those who start shaving prior to 16 years of age and those $175-180 \mathrm{~cm}$ in height had a greater than seven fold increased risk of being diagnosed with high grade cancer on their prostate biopsy compared to those $<175 \mathrm{~cm}$.

In a case control study of 1,088 Spanish patients diagnosed with PCa, Lope et al. similarly demonstrated that risk of PCa rose by $6 \%$ for each year of delayed puberty onset, with this risk significantly increased in those reaching puberty after 15 years of age (OR 1.35, 95\% CI: 1.08-1.68) (8). These results however were not corroborated in two other studies that found no association between age of first shave and risk of $\mathrm{PCa}(5,9)$. Similarly, patient height was not found to be associated with risk of PCa $(8,9)$. Nair-Shalliker et al. demonstrated that both later (versus same as peers; $\mathrm{OR}=0.75,95 \%$ CI: $0.59-0.97)$ and earlier (OR=0.85, 95\% CI: $0.61-1.17)$ onsets of puberty were associated with risk of $\mathrm{PCa}$ (10). In a population-based, case-control study from Australia between 1994 and 1998, Giles et al. demonstrated that having a growth spurt later than friends reduced risk (OR 0.79, 95\% CI: $0.63-0.97$ ) of PCa (11).

Our findings suggest that patients with later age of puberty, and thus later testosterone surges, are at increased risk of overall and high grade $\mathrm{PCa}$, which contradicts our earlier hypothesis of increased PCa risk with prolonged androgen exposure. A possible explanation for these findings may be related to insulin-like growth factor (IGF-1) levels. IGF-1 is vital for cellular differentiation, proliferation, transformation, and apoptosis, and increased levels have been positively associated with PCa risk $(12,13)$. IGF-1 levels increase rapidly during puberty and then drop during adulthood (14). A delay in IGF-1 level peaks in patients with delayed puberty may thus, theoretically, be an underlying cause of increased PCa risk in such patients.

While increased testosterone levels have long been accepted as a risk factor for PCa pathogenesis, and treatments for advanced PCa target androgen suppression (15), there has been increasing evidence to suggest that patients 
Table 2 Predictors of presence of cancer on prostate biopsy, high grade cancer, and high-volume cancer (multivariable ${ }^{\dagger}$ )

\begin{tabular}{|c|c|c|c|}
\hline Variable & OR & $95 \% \mathrm{Cl}$ & $P$ value \\
\hline \multicolumn{4}{|c|}{ Predictors of presence of cancer on prostate biopsy } \\
\hline \multicolumn{4}{|c|}{ Age of first shave (categorical, reference: <16) } \\
\hline $16-18$ & 1.90 & $0.59-4.55$ & 0.28 \\
\hline$>18$ & 5.34 & $1.15-9.39$ & 0.02 \\
\hline $175-180 \mathrm{~cm}$ & 1.26 & $0.49-3.30$ & 0.61 \\
\hline$>180 \mathrm{~cm}$ & 1.81 & $0.82-4.20$ & 0.15 \\
\hline \multicolumn{4}{|c|}{ Predictors of high-grade cancer on prostate biopsy } \\
\hline \multicolumn{4}{|c|}{ Age of first shave (categorical, reference: $<16$ ) } \\
\hline \multicolumn{4}{|c|}{ Height (categorical, reference: $<175 \mathrm{~cm}$ ) } \\
\hline $175-180 \mathrm{~cm}$ & 7.46 & $4.41-9.47$ & 0.037 \\
\hline$>180 \mathrm{~cm}$ & 2.68 & $0.86-8.26$ & 0.19 \\
\hline \multicolumn{4}{|c|}{ Predictors of high-volume cancer on prostate biopsy } \\
\hline \multicolumn{4}{|c|}{ Age of first shave (categorical, reference: <16) } \\
\hline $16-18$ & 11.55 & $0.97-18.48$ & 0.057 \\
\hline$>18$ & 8.99 & $0.91-11.30$ & 0.79 \\
\hline \multicolumn{4}{|c|}{ Height (categorical, reference: $<175 \mathrm{~cm}$ ) } \\
\hline
\end{tabular}

${ }^{\dagger}$, controlling for patient age, race, prostate specific antigen, \% free prostate specific antigen, clinical stage, prostate volume, body mass index, family history.

presenting for a prostate biopsy, and thus at high baseline risk for PCa, may have lower levels of testosterone $(16,17)$. In a prospective study of patients with high grade prostatic intraepithelial neoplasia undergoing a re-biopsy, Garcia-Cruz et al. demonstrated that patients with lower free testosterone levels exhibited increased risk of $\mathrm{PCa}(18)$. These findings are further supported by additional studies demonstrating that patients with lower testosterone levels at time of prostate biopsy had higher odds of being diagnosed with PCa (19,20). Additionally, such patients may also be at increased risk of diagnosis with high grade disease $(21,22)$. We must highlight however the observational nature of these studies that evaluate associations, which are often biased by multiple confounders and thus subject to selection biases, and not causation.
Our results may also be partly explained by the crosssectional nature of this study. Patients referred for a prostate biopsy are at higher risk for PCa than the general population, and thus have a higher pre-test probability of a positive prostate biopsy. It can also be argued that patients with shorter duration of exposure to high androgen levels (i.e., those with delayed puberty) are expected to have lower serum PSA levels (23), and thus those referred for a prostate biopsy, often due to an elevated PSA measurement, are actually at an inherently higher risk of having underlying malignancy explaining the increased odds of a positive prostate biopsy in our cohort.

In addition to a potential selection bias, there may be a recall bias related to having patients self-report their age of first shave. These patients may also have had varying 
"thresholds" to start shaving, potentially influenced by social factors. Age of first shave was not available in $52.7 \%$ of patients, with missing data a source of potential bias. However, sensitivity analyses of the subcohort of patients without missing data $(\mathrm{n}=1,176)$ demonstrated consistent results suggesting that the data may be missing at random. Furthermore, the cutoffs for the categorical variables of age of first shave and height were chosen by a consensus of the authors with choice of cutoffs potentially influence the significance of the results obtained. As a patient's BMI is derived from his height and weight, including both height and BMI variables in the multivariable models may have introduced collinearity, influencing the significance of the results. As patients in our cohort were recruited from 1995 , a significant proportion (45.9\%) did not undergo a twelve core prostate biopsy, which is the current standard of practice (24). No differences were seen however in baseline characteristics of patients undergoing a twelve versus nontwelve core biopsy. Given that our study period spanned two decades, prostate biopsies were likely performed by different providers, which may have potentially temporally impacted the accuracy of the biopsy results.

\section{Conclusions}

Amongst patients presenting for a prostate biopsy, those with a later age of first shave and increased adult height have an increased risk of a positive prostate biopsy and high grade $\mathrm{PCa}$, respectively. These results suggest that androgen levels variations in early age may potentially impact risk of PCa pathogenesis later in adulthood.

\section{Acknowledgments}

Poster Presentations: Genitourinary Cancers Symposium (American Society of Clinical Oncology), and the Southeastern Section of the AUA $85^{\text {th }}$ Annual Meeting.

Funding: None.

\section{Footnote}

Reporting Checklist: The authors have completed the STROBE reporting checklist. Available at https://dx.doi. org/10.21037/tau-21-433

Data Sharing Statement: Available at https://dx.doi. org/10.21037/tau-21-43
Peer Review File: Available at https://dx.doi.org/10.21037/ tau-21-433

Conflicts of Interest: All authors have completed the ICMJE uniform disclosure form (available at https://dx.doi. org/10.21037/tau-21-433). The authors have no conflicts of interest to declare.

Ethical Statement: The authors are accountable for all aspects of the work in ensuring that questions related to the accuracy or integrity of any part of the work are appropriately investigated and resolved. The trial was conducted in accordance with the Declaration of Helsinki (as revised in 2013). The study was approved by the institutional review board of Augusta University (IRB No. 611094) and informed consent was taken from all individual participants.

Open Access Statement: This is an Open Access article distributed in accordance with the Creative Commons Attribution-NonCommercial-NoDerivs 4.0 International License (CC BY-NC-ND 4.0), which permits the noncommercial replication and distribution of the article with the strict proviso that no changes or edits are made and the original work is properly cited (including links to both the formal publication through the relevant DOI and the license). See: https://creativecommons.org/licenses/by-nc-nd/4.0/.

\section{References}

1. Lee DJ, Mallin K, Graves AJ, et al. Recent Changes in Prostate Cancer Screening Practices and Epidemiology. J Urol 2017;198:1230-40.

2. Sánchez-Chapado $M$, Olmedilla $G$, Cabeza $M$, et al. Prevalence of prostate cancer and prostatic intraepithelial neoplasia in Caucasian Mediterranean males: an autopsy study. Prostate 2003;54:238-47.

3. Sakr WA, Haas GP, Cassin BF, et al. The frequency of carcinoma and intraepithelial neoplasia of the prostate in young male patients. J Urol 1993;150:379-85.

4. Lee PA, Migeon CJ. Puberty in boys: correlation of plasma levels of gonadotropins (LH, FSH), androgens (testosterone, androstenedione, dehydroepiandrosterone and its sulfate), estrogens (estrone and estradiol) and progestins (progesterone and 17-hydroxyprogesterone). J Clin Endocrinol Metab 1975;41:556-62.

5. Barba $M$, Terrenato I, Schünemann HJ, et al. Indicators 
of sexual and somatic development and adolescent body size in relation to prostate cancer risk: results from a casecontrol study. Urology 2008;72:183-7.

6. Shim KS. Pubertal growth and epiphyseal fusion. Ann Pediatr Endocrinol Metab 2015;20:8-12.

7. Håkonsen LB, Brath-Lund ML, Hounsgaard ML, et al. In utero exposure to alcohol and puberty in boys: a pregnancy cohort study. BMJ Open 2014;4:e004467.

8. Lope V, García-Esquinas E, Ruiz-Dominguez JM, et al. Perinatal and childhood factors and risk of prostate cancer in adulthood: MCC-Spain case-control study. Cancer Epidemiol 2016;43:49-55.

9. Habel LA, Van Den Eeden SK, Friedman GD. Body size, age at shaving initiation, and prostate cancer in a large, multiracial cohort. Prostate 2000;43:136-43.

10. Nair-Shalliker V, Yap S, Nunez C, et al. Adult body size, sexual history and adolescent sexual development, may predict risk of developing prostate cancer: Results from the New South Wales Lifestyle and Evaluation of Risk Study (CLEAR). Int J Cancer 2017;140:565-74.

11. Giles GG, Severi G, English DR, et al. Early growth, adult body size and prostate cancer risk. Int J Cancer 2003;103:241-5.

12. Gennigens C, Menetrier-Caux C, Droz JP. Insulin-Like Growth Factor (IGF) family and prostate cancer. Crit Rev Oncol Hematol 2006;58:124-45.

13. Rowlands MA, Gunnell D, Harris R, et al. Circulating insulin-like growth factor peptides and prostate cancer risk: a systematic review and meta-analysis. Int J Cancer 2009; 124:2416-29.

14. Juul A, Bang P, Hertel NT, et al. Serum insulin-like growth factor-I in 1030 healthy children, adolescents, and adults: relation to age, sex, stage of puberty, testicular size, and body mass index. J Clin Endocrinol Metab 1994;78:744-52.

Cite this article as: Khadir RM, Sayyid RK, Matthews B, King SA, Terris MK. Impact of early hypothalamic-pituitary-gonadal axis maturation on prostate cancer: cross-sectional analysis of a Veterans affairs cohort. Transl Androl Urol 2021;10(8):3368-3374. doi: 10.21037/tau-21-433
15. Cornford P, Bellmunt J, Bolla M, et al. EAU-ESTROSIOG Guidelines on Prostate Cancer. Part II: Treatment of Relapsing, Metastatic, and Castration-Resistant Prostate Cancer. Eur Urol 2017;71:630-42.

16. Michaud JE, Billups KL, Partin AW. Testosterone and prostate cancer: an evidence-based review of pathogenesis and oncologic risk. Ther Adv Urol 2015;7:378-87.

17. Gann PH, Hennekens CH, Ma J, et al. Prospective study of sex hormone levels and risk of prostate cancer. J Natl Cancer Inst 1996;88:1118-26.

18. García-Cruz E, Piqueras M, Ribal MJ, et al. Low testosterone level predicts prostate cancer in re-biopsy in patients with high grade prostatic intraepithelial neoplasia. BJU Int 2012;110:E199-202.

19. Sofikerim M, Eskicorapci S, Oruç O, et al. Hormonal predictors of prostate cancer. Urol Int 2007;79:13-8.

20. Shin BS, Hwang EC, Im CM, et al. Is a decreased serum testosterone level a risk factor for prostate cancer? A cohort study of korean men. Korean J Urol 2010;51:819-23.

21. Yano M, Imamoto T, Suzuki H, et al. The clinical potential of pretreatment serum testosterone level to improve the efficiency of prostate cancer screening. Eur Urol 2007;51:375-80.

22. Scott PA Sr, Perkash I, Mode D, et al. Prostate cancer diagnosed in spinal cord-injured patients is more commonly advanced stage than in able-bodied patients. Urology 2004;63:509-12.

23. Boyle P, Koechlin A, Bota M, et al. Endogenous and exogenous testosterone and the risk of prostate cancer and increased prostate-specific antigen (PSA) level: a metaanalysis. BJU Int 2016;118:731-41.

24. Carter HB, Albertsen PC, Barry MJ, et al. Early detection of prostate cancer: AUA Guideline. J Urol 2013;190:419-26. 


\section{Supplementary}

Table S1 Baseline patient characteristics by number of biopsy cores taken

\begin{tabular}{|c|c|c|c|}
\hline Variable & Twelve core biopsy group $(n=1,326)$ & Non-twelve core biopsy group $(n=1,130)$ & P-value \\
\hline Age in years, median (IQR) & $61.0(57.2-64.6)$ & $61.5(55.7-66.5)$ & $0.68^{\mathrm{a}}$ \\
\hline Race, n (\%) & & & $0.96^{\mathrm{b}}$ \\
\hline African American & $640(48.3 \%)$ & $559(49.5 \%)$ & \\
\hline Caucasian & $651(49.1 \%)$ & $545(48.2 \%)$ & \\
\hline Other & $32(2.41 \%)$ & $29(2.57 \%)$ & \\
\hline BMI in $\mathrm{kg} / \mathrm{m}^{2}$, median (IQR) & $28.9(26.0-32.7)$ & $28.4(25.1-32.0)$ & $0.32^{\mathrm{a}}$ \\
\hline Height in cm, median (IQR) & $177.7(172.4-182.8)$ & $177.7(172.7-183.0)$ & $0.83^{\mathrm{a}}$ \\
\hline Age of first shaving in years, median (IQR) & $17.0(16.0-18.7)$ & $17.0(16.0-18.7)$ & $0.89^{\mathrm{a}}$ \\
\hline PSA in ng/ml, median (IQR) & $5.47(4.32-7.72)$ & $5.73(4.19-8.97)$ & $0.47^{\mathrm{a}}$ \\
\hline \% Free PSA, median (IQR) & $14.2(9.90-19.7)$ & $14.9(9.87-19.7)$ & $0.42^{a}$ \\
\hline Clinical T Stage, n (\%) & & & $0.52^{b}$ \\
\hline$\leq \mathrm{T} 1 \mathrm{c}$ & $913(68.9 \%)$ & $757(67.0 \%)$ & \\
\hline T2 & $404(30.5 \%)$ & $333(29.5 \%)$ & \\
\hline$\geq T 3$ & $28(2.11 \%)$ & $21(1.86 \%)$ & \\
\hline Prostate volume in cc, median (IQR) & $38.9(29.0-54.1)$ & $37.6(27.9-52.7)$ & $0.18^{a}$ \\
\hline Positive prostate biopsies, n (\%) & $676(51.0 \%)$ & $581(51.4 \%)$ & $0.19^{b}$ \\
\hline Gleason Score, n (\%) & & & $025^{b}$ \\
\hline$\leq 6(3+3)$ & $277(41.0 \%)$ & $211(36.3 \%)$ & \\
\hline $7(3+4)$ & $130(19.2 \%)$ & $136(23.4 \%)$ & \\
\hline $7(4+3)$ & $110(16.3 \%)$ & $100(17.2 \%)$ & \\
\hline $8(4+4)$ & $106(15.7 \%)$ & $96(16.5 \%)$ & \\
\hline$\geq 9$ & $53(7.84 \%)$ & $38(6.54 \%)$ & \\
\hline Percent positive cores, median (IQR) & $19.7 \%(9.0 \%-33.3 \%)$ & $18.3 \%(12.0-25.0)$ & $0.19^{\mathrm{a}}$ \\
\hline
\end{tabular}

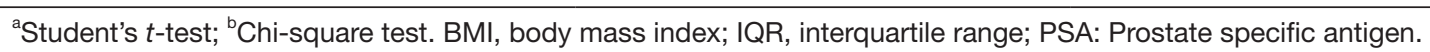


Table S2 Predictors of presence of cancer on prostate biopsy (univariable)

\begin{tabular}{|c|c|c|c|}
\hline Variable & OR & $95 \% \mathrm{Cl}$ & P-value \\
\hline \multicolumn{4}{|c|}{ Age of first shave (Reference: $<16$ years) } \\
\hline $16-18$ & 1.50 & $1.18-2.102$ & 0.006 \\
\hline$>18$ & 1.30 & $0.92-1.74$ & 0.15 \\
\hline \multicolumn{4}{|l|}{ Height (Reference: <175 cm) } \\
\hline $175-180$ & 0.97 & $0.82-1.21$ & 0.89 \\
\hline$>180$ & 0.98 & $0.76-1.17$ & 0.68 \\
\hline \multicolumn{4}{|l|}{ Age at biopsy (Reference: 50-59) } \\
\hline$<50$ & 0.99 & $0.72-1.40$ & 0.96 \\
\hline $60-69$ & 1.09 & $0.94-1.28$ & 0.29 \\
\hline $70+$ & 0.99 & $0.77-1.28$ & 0.92 \\
\hline \multicolumn{4}{|l|}{ Race (Reference: Caucasian) } \\
\hline African American & 1.94 & $1.67-2.20$ & $<0.001$ \\
\hline Other & 1.13 & $0.55-2.23$ & 0.72 \\
\hline \multicolumn{3}{|c|}{ Race*Age of first shave (Race reference: Caucasian, Age of first shave reference: $<16$ years) } & 0.53 \\
\hline African American * $16-18$ years & 0.79 & $0.41-1.50$ & 0.55 \\
\hline Other * $16-18$ years & 8.60 & $0.48-32.0$ & 0.98 \\
\hline African American * $>18$ years & 0.84 & $0.44-1.58$ & 0.54 \\
\hline Other ${ }^{*}>18$ years & 2.06 & $0.60-7.23$ & 0.97 \\
\hline \multicolumn{3}{|c|}{ Race*Height (Race reference: Caucasian, Height reference: $<175 \mathrm{~cm}$ ) } & 0.38 \\
\hline African American * $175-180 \mathrm{~cm}$ & 1.15 & $0.76-1.60$ & 0.58 \\
\hline Other * $175-180 \mathrm{~cm}$ & 0.93 & $0.16-5.06$ & 0.94 \\
\hline African American * $>180 \mathrm{~cm}$ & 1.02 & $0.68-1.49$ & 0.95 \\
\hline Other * $>180 \mathrm{~cm}$ & 2.08 & $0.69-6.67$ & 0.37 \\
\hline \multicolumn{4}{|l|}{ PSA (Reference: 0-4 ng/ml) } \\
\hline $4-10$ & 2.50 & $2.07-3.10$ & $<0.001$ \\
\hline $10-20$ & 2.72 & $2.00-3.59$ & $<0.001$ \\
\hline $20+$ & 7.91 & $5.28-11.87$ & $<0.001$ \\
\hline \multicolumn{4}{|l|}{ Free PSA (Reference: <10\%) } \\
\hline $10-20 \%$ & 0.40 & $0.27-0.61$ & $<0.001$ \\
\hline$>20 \%$ & 0.24 & $0.16-0.33$ & $<0.001$ \\
\hline Clinical stage $(\geq \mathrm{T} 2$ versus $\leq \mathrm{T} 1)$ & 0.92 & $0.78-1.12$ & 0.12 \\
\hline \multicolumn{4}{|l|}{ TRUS Volume (Reference: <40 cc) } \\
\hline $40-80 \mathrm{cc}$ & 0.45 & $0.43-0.52$ & $<0.001$ \\
\hline$>80$ & 0.23 & $0.17-0.29$ & $<0.001$ \\
\hline \multicolumn{4}{|l|}{ BMI (Reference: $18.5-24.9$ kg/m²) } \\
\hline$<18.5$ & 0.98 & $0.53-1.88$ & 0.94 \\
\hline $25-29.9$ & 0.92 & $0.76-1.13$ & 0.56 \\
\hline $30-34.9$ & 0.90 & $0.75-1.12$ & 0.40 \\
\hline$>35$ & 1.08 & $0.82-1.39$ & 0.62 \\
\hline Family history (yes vs. no) & 1.57 & $1.19-2.06$ & $<0.001$ \\
\hline
\end{tabular}

BMI, body mass index; $\mathrm{Cl}$, confidence interval; OR, odds ratio; PSA, prostate-specific antigen; TRUS, transrectal ultrasound. 
Table S3 Predictors of presence of high grade cancer on prostate biopsy (Univariable)

\begin{tabular}{|c|c|c|c|}
\hline Variable & OR & $95 \% \mathrm{Cl}$ & P-value \\
\hline \multicolumn{4}{|c|}{ Age of first shave (Reference: $<16$ years) } \\
\hline $16-18$ & 1.01 & $0.62-1.66$ & 0.96 \\
\hline$>18$ & 0.79 & $0.42-1.32$ & 0.33 \\
\hline \multicolumn{4}{|l|}{ Height (Reference: <175 cm) } \\
\hline $175-180$ & 0.86 & $0.60-1.15$ & 0.26 \\
\hline$>180$ & 0.90 & $0.70-1.27$ & 0.70 \\
\hline \multicolumn{4}{|l|}{ Age at biopsy (Reference: 50-59) } \\
\hline$<50$ & 0.65 & $0.28-1.17$ & 0.19 \\
\hline $60-69$ & 1.06 & $0.78-1.38$ & 0.83 \\
\hline $70+$ & 2.42 & $1.60-3.36$ & $<0.001$ \\
\hline \multicolumn{4}{|l|}{ Race (Reference: Caucasian) } \\
\hline African American & 1.66 & $1.32-2.17$ & $<0.001$ \\
\hline Other & 0.31 & $0.016-1.35$ & 0.23 \\
\hline \multicolumn{3}{|c|}{ Race ${ }^{\star}$ Age of first shave (Race reference: Caucasian, Age of first shave reference: $<16$ years) } & 0.29 \\
\hline African American * $16-18$ years & 0.61 & $0.24-1.77$ & 0.28 \\
\hline Other * $16-18$ years & 0.79 & $0.35-2.44$ & 0.85 \\
\hline African American * $>18$ years & 0.90 & $0.61-1.74$ & 0.87 \\
\hline Other * $^{*} 18$ years & 1.33 & $0.59-2.90$ & 0.85 \\
\hline \multicolumn{3}{|c|}{ Race Height (Race reference: Caucasian, Height reference: $<175 \mathrm{~cm}$ ) } & 0.82 \\
\hline African American * $175-180 \mathrm{~cm}$ & 1.01 & $0.55-1.88$ & 0.74 \\
\hline Other * $175-180 \mathrm{~cm}$ & 0.43 & $0.12-1.67$ & 0.86 \\
\hline African American * $>180 \mathrm{~cm}$ & 1.03 & $0.59-1.77$ & 0.69 \\
\hline Other ${ }^{*}>180 \mathrm{~cm}$ & 0.42 & $0.15-1.40$ & 0.94 \\
\hline \multicolumn{4}{|l|}{ PSA (Reference: 0-4 ng/ml) } \\
\hline $4-10$ & 2.60 & $1.68-4.18$ & $<0.001$ \\
\hline $10-20$ & 3.98 & $2.37-6.70$ & $<0.001$ \\
\hline $20+$ & 19.64 & $11.9-34.0$ & $<0.001$ \\
\hline \multicolumn{4}{|l|}{ Free PSA (Reference: <10\%) } \\
\hline $10-20 \%$ & 0.24 & $0.14-0.545$ & $<0.001$ \\
\hline$>20 \%$ & 0.19 & $0.079-0.40$ & $<0.001$ \\
\hline Clinical stage $(\geq \mathrm{T} 2$ versus $\leq \mathrm{T} 1)$ & 1.62 & $1.13-1.68$ & 0.005 \\
\hline \multicolumn{4}{|l|}{ TRUS Volume (Reference: <40 cc) } \\
\hline $40-80 \mathrm{cc}$ & 0.57 & $0.49-0.65$ & $<0.001$ \\
\hline$>80$ & 0.20 & $0.12-0.39$ & $<0.001$ \\
\hline \multicolumn{4}{|l|}{ BMI (Reference: $18.5-24.9$ kg/m²) } \\
\hline$<18.5$ & 0.99 & $0.30-2.46$ & 0.98 \\
\hline $25-29.9$ & 0.66 & $0.47-0.84$ & 0.0043 \\
\hline $30-34.9$ & 0.80 & $0.52-1.10$ & 0.25 \\
\hline$>35$ & 1.10 & $0.75-1.44$ & 0.72 \\
\hline Family history (yes vs. no) & 1.13 & $0.79-1.55$ & 0.59 \\
\hline
\end{tabular}

BMI, body mass index; $\mathrm{Cl}$, confidence interval; OR, odds ratio; PSA, prostate-specific antigen; TRUS, transrectal ultrasound. 
Table S4 Predictors of presence of high volume cancer on prostate biopsy (univariable)

\begin{tabular}{|c|c|c|c|}
\hline Variable & OR & $95 \% \mathrm{Cl}$ & P-value \\
\hline \multicolumn{4}{|c|}{ Age of first shave (Reference: $<16$ years) } \\
\hline $16-18$ & 1.07 & $0.72-1.69$ & 0.72 \\
\hline$>18$ & 1.04 & $0.66-1.62$ & 0.88 \\
\hline \multicolumn{4}{|l|}{ Height (Reference: <175 cm) } \\
\hline $175-180$ & 1.00 & $0.79-1.30$ & 0.98 \\
\hline$>180$ & 0.98 & $0.79-1.25$ & 0.89 \\
\hline \multicolumn{4}{|l|}{ Age at biopsy (Reference: 50-59) } \\
\hline$<50$ & 0.63 & $0.42-1.06$ & 0.09 \\
\hline $60-69$ & 0.88 & $0.70-1.09$ & 0.34 \\
\hline $70+$ & 1.52 & $1.14-2.00$ & 0.012 \\
\hline \multicolumn{4}{|l|}{ Race (Reference: Caucasian) } \\
\hline African American & 1.58 & $1.35-1.892$ & $<0.001$ \\
\hline Other & 1.36 & $0.54-2.99$ & 0.46 \\
\hline \multicolumn{3}{|c|}{ Race ${ }^{\star}$ Age of first shave (Race reference: Caucasian, Age of first shave reference: $<16$ years) } & 0.35 \\
\hline African American * $16-18$ years & 0.64 & $0.29-1.41$ & 0.27 \\
\hline Other * $16-18$ years & 2.88 & $0.77-5.07$ & 0.96 \\
\hline African American * $>18$ years & 0.93 & $0.7-2.35$ & 0.85 \\
\hline Other $^{*}>18$ years & 2.43 & $0.55-4.02$ & 0.96 \\
\hline \multicolumn{3}{|c|}{ Race*Height (Race reference: Caucasian, Height reference: $<175 \mathrm{~cm}$ ) } & 0.41 \\
\hline African American * $175-180 \mathrm{~cm}$ & 1.30 & $0.78-2.14$ & 0.37 \\
\hline Other * $175-180 \mathrm{~cm}$ & 2.16 & $0.26-6.89$ & 0.46 \\
\hline African American * $>180 \mathrm{~cm}$ & 1.03 & $0.65-1.65$ & 0.89 \\
\hline Other ${ }^{*}>180 \mathrm{~cm}$ & 1.96 & $0.25-15.4$ & 0.49 \\
\hline \multicolumn{4}{|l|}{ PSA (Reference: 0-4 ng/ml) } \\
\hline $4-10$ & 2.55 & $1.79-3.70$ & $<0.001$ \\
\hline $10-20$ & 3.56 & $2.40-5.46$ & $<0.001$ \\
\hline $20+$ & 18.9 & $12.0-30.2$ & $<0.001$ \\
\hline \multicolumn{4}{|l|}{ Free PSA (Reference: <10\%) } \\
\hline $10-20 \%$ & 0.45 & $0.28-0.70$ & 0.003 \\
\hline$>20 \%$ & 0.23 & $0.12-0.44$ & $<0.001$ \\
\hline Clinical stage $(\geq T 2$ versus $\leq T 1)$ & 1.53 & $1.22-1.93$ & 0.001 \\
\hline \multicolumn{4}{|l|}{ TRUS Volume (Reference: <40 cc) } \\
\hline $40-80 \mathrm{cc}$ & 0.42 & $0.36-0.56$ & $<0.001$ \\
\hline$>80$ & 0.10 & $0.039-0.20$ & $<0.001$ \\
\hline \multicolumn{4}{|l|}{ BMI (Reference: $18.5-24.9 \mathrm{~kg} / \mathrm{m}^{2}$ ) } \\
\hline$<18.5$ & 0.73 & $0.27-1.60$ & 0.43 \\
\hline $25-29.9$ & 0.66 & $0.52-0.81$ & $<0.001$ \\
\hline $30-34.9$ & 0.75 & $0.55-0.99$ & 0.043 \\
\hline$>35$ & 0.76 & $0.49-1.06$ & 0.13 \\
\hline Family history (yes vs. no) & 1.49 & $1.10-1.95$ & 0.014 \\
\hline
\end{tabular}

BMI, body mass index; $\mathrm{Cl}$, confidence interval; OR, odds ratio; PSA, prostate-specific antigen; TRUS, transrectal ultrasound. 
Table S5 Association between patient characteristics and prostate volume on ultrasound at biopsy (univariable)

\begin{tabular}{|c|c|c|c|}
\hline Variable & OR & $95 \% \mathrm{Cl}$ & P-value \\
\hline \multicolumn{4}{|c|}{ Age of first shave (Reference: $<16$ years) } \\
\hline $16-18$ & 0.99 & $0.88-1.12$ & 0.77 \\
\hline$>18$ & 0.99 & $0.90-1.10$ & 0.89 \\
\hline \multicolumn{4}{|l|}{ Height (Reference: <175 cm) } \\
\hline $175-180$ & 1.10 & $1.04-1.14$ & 0.022 \\
\hline$>180$ & 1.11 & $1.05-1.16$ & $<0.001$ \\
\hline \multicolumn{4}{|l|}{ Age at biopsy (Reference: 50-59) } \\
\hline$<50$ & 1.29 & $1.19-1.44$ & $<0.001$ \\
\hline $60-69$ & 1.47 & $1.36-1.60$ & $<0.001$ \\
\hline $70+$ & 1.72 & $1.55-1.90$ & $<0.001$ \\
\hline \multicolumn{4}{|l|}{ Race (Reference: Caucasian) } \\
\hline African American & 1.04 & $0.99-1.07$ & 0.10 \\
\hline Other & 1.01 & $0.85-1.22$ & 0.92 \\
\hline \multicolumn{4}{|l|}{ PSA (Reference: 0-4 ng/ml) } \\
\hline $4-10$ & 1.20 & $1.14-12.4$ & $<0.001$ \\
\hline $10-20$ & 1.45 & $1.35-1.55$ & $<0.001$ \\
\hline $20+$ & 1.55 & $1.40-1.68$ & $<0.001$ \\
\hline \multicolumn{4}{|l|}{ Free PSA (Reference: <10\%) } \\
\hline $10-20 \%$ & 1.36 & $1.23-1.50$ & $<0.001$ \\
\hline$>20 \%$ & 1.70 & $1.52-1.91$ & $<0.001$ \\
\hline Clinical stage $(\geq \mathrm{T} 2$ versus $\leq \mathrm{T} 1)$ & 0.87 & $0.84-0.91$ & $<0.001$ \\
\hline \multicolumn{4}{|l|}{ BMI (Reference: $18.5-24.9$ kg/m²) } \\
\hline$<18.5$ & 1.20 & $1.01-1.42$ & 0.030 \\
\hline $25-29.9$ & 1.33 & $1.10-1.57$ & 0.004 \\
\hline $30-34.9$ & 1.48 & $1.23-1.75$ & $<0.001$ \\
\hline$>35$ & 1.49 & $1.22-1.75$ & $<0.001$ \\
\hline Family history (yes vs. no) & 0.99 & $0.93-1.06$ & 0.68 \\
\hline
\end{tabular}

BMI, body mass index; $\mathrm{Cl}$, confidence interval; OR, odds ratio; PSA, prostate-specific antigen.

Table S6 Association between patient characteristics and prostate volume on ultrasound at biopsy (multivariable*)

\begin{tabular}{lcc}
\hline Age of first shave (categorical, reference: $<16)$ & OR & $95 \% \mathrm{Cl}$ \\
\hline $16-18$ & 1.08 & $0.91-1.40$ \\
$>18$ & 1.12 & $0.88-1.45$ \\
Height (categorical, reference: $<175 \mathrm{~cm}$ ) & & 0.34 \\
$175-180 \mathrm{~cm}$ & 0.95 & $0.82-1.14$ \\
$>180 \mathrm{~cm}$ & 1.00 & $0.84-1.18$
\end{tabular}

${ }^{*}$ Controlling for patient age, race, prostate specific antigen, \% free prostate specific antigen, clinical stage, body mass index, family history. 
Table S7 Baseline patient characteristics for the subcohort of patients with no missing data $(\mathrm{n}=1,176)$

\begin{tabular}{|c|c|}
\hline & Value \\
\hline Age in years, median (IQR) & $61.0(57.0-66.0)$ \\
\hline \multicolumn{2}{|l|}{ Race, n (\%) } \\
\hline African American & $572(48.6 \%)$ \\
\hline Caucasian & $574(48.9 \%)$ \\
\hline Other & $30(2.6 \%)$ \\
\hline $\mathrm{BMI}$ in $\mathrm{kg} / \mathrm{m}^{2}$, median (IQR) & $28.6(25.5-32.4)$ \\
\hline Height in cm, median (IQR) & $177.8(172.7-182.9)$ \\
\hline \multicolumn{2}{|l|}{ Height in cm, n (\%) } \\
\hline$<175 \mathrm{~cm}$ & $359(30.6 \%)$ \\
\hline $175-180 \mathrm{~cm}$ & 306 (26.0\%) \\
\hline$>180 \mathrm{~cm}$ & $511(43.4 \%)$ \\
\hline Age of first shaving in years, median (IQR) & $17.0(16.0-19.0)$ \\
\hline \multicolumn{2}{|l|}{ Age of first shaving in years, $n(\%)$} \\
\hline$<16$ years & $239(20.3 \%)$ \\
\hline $16-18$ years & $623(53.0 \%)$ \\
\hline$>18$ years & $314(26.7 \%)$ \\
\hline PSA in $\mathrm{ng} / \mathrm{ml}$, median (IQR) & $5.7(4.4-8.2)$ \\
\hline \% Free PSA, median (IQR) & $14.8(10.0-19.0)$ \\
\hline \multicolumn{2}{|l|}{ Clinical T Stage, n (\%) } \\
\hline$\leq T 1 \mathrm{c}$ & $823(70.0 \%)$ \\
\hline T2 & $328(27.9 \%)$ \\
\hline$\geq T 3$ & $25(2.1 \%)$ \\
\hline Prostate volume in cc, median (IQR) & $38.0(28.0-53.3)$ \\
\hline Positive prostate biopsies, n (\%) & 599 (50.9\%) \\
\hline \multicolumn{2}{|l|}{ Gleason Score, n (\%) } \\
\hline$\leq 6(3+3)$ & $233(39.0 \%)$ \\
\hline $7(3+4)$ & $125(20.9 \%)$ \\
\hline $7(4+3)$ & 100 (16.7\%) \\
\hline $8(4+4)$ & $97(16.2 \%)$ \\
\hline$\geq 9$ & $44(7.3 \%)$ \\
\hline Percent positive cores, median (IQR) & $18.6 \%(4.2-30.0 \%)$ \\
\hline
\end{tabular}


Table S8 Predictors of presence of cancer on prostate biopsy, high grade cancer, and high volume cancer (multivariable*) in the subcohort of patients with no missing data $(\mathrm{n}=1,176)$

\begin{tabular}{|c|c|c|c|}
\hline Variable & OR & $95 \% \mathrm{Cl}$ & $P$ value \\
\hline \multicolumn{4}{|c|}{ Predictors of presence of cancer on prostate biopsy } \\
\hline \multicolumn{4}{|c|}{ Age of first shave (categorical, reference: $<16$ ) } \\
\hline $16-18$ & 1.88 & $0.55-4.71$ & 0.32 \\
\hline$>18$ & 5.36 & $1.13-9.53$ & 0.03 \\
\hline \multicolumn{4}{|c|}{ Height (categorical, reference: $<175 \mathrm{~cm}$ ) } \\
\hline $175-180 \mathrm{~cm}$ & 1.30 & $0.51-3.37$ & 0.59 \\
\hline$>180 \mathrm{~cm}$ & 1.82 & $0.80-4.24$ & 0.16 \\
\hline \multicolumn{4}{|c|}{ Predictors of high-grade cancer on prostate biopsy } \\
\hline \multicolumn{4}{|c|}{ Age of first shave (categorical, reference: $<16$ ) } \\
\hline $16-18$ & 0.45 & $0.05-4.30$ & 0.48 \\
\hline$>18$ & 0.17 & $0.008-2.36$ & 0.21 \\
\hline \multicolumn{4}{|c|}{ Height (categorical, reference: $<175 \mathrm{~cm}$ ) } \\
\hline $175-180 \mathrm{~cm}$ & 7.41 & $4.25-9.48$ & 0.038 \\
\hline$>180 \mathrm{~cm}$ & 2.62 & $0.82-8.19$ & 0.21 \\
\hline \multicolumn{4}{|c|}{ Predictors of high-volume cancer on prostate biopsy } \\
\hline \multicolumn{4}{|c|}{ Age of first shave (categorical, reference: $<16$ ) } \\
\hline $16-18$ & 11.56 & $0.98-18.46$ & 0.055 \\
\hline$>18$ & 8.97 & $0.89-11.32$ & 0.080 \\
\hline \multicolumn{4}{|c|}{ Height (categorical, reference: $<175 \mathrm{~cm}$ ) } \\
\hline $175-180 \mathrm{~cm}$ & 2.34 & $0.82-4.12$ & 0.13 \\
\hline$>180 \mathrm{~cm}$ & 1.82 & $0.78-4.93$ & 0.21 \\
\hline
\end{tabular}


Table S9 Predictors of presence of cancer on prostate biopsy (univariable) in the subcohort of patients with no missing data (n=1,176)

\begin{tabular}{|c|c|c|c|}
\hline Variable & OR & $95 \% \mathrm{Cl}$ & P-value \\
\hline \multicolumn{4}{|c|}{ Age of first shave (Reference: $<16$ years) } \\
\hline $16-18$ & 1.56 & $1.15-2.11$ & 0.005 \\
\hline$>18$ & 1.26 & $0.90-1.78$ & 0.18 \\
\hline \multicolumn{4}{|l|}{ Height (Reference: <175 cm) } \\
\hline $175-180$ & 0.98 & $0.81-1.20$ & 0.88 \\
\hline$>180$ & 0.96 & $0.80-1.14$ & 0.64 \\
\hline \multicolumn{4}{|l|}{ Age at biopsy (Reference: 50-59) } \\
\hline$<50$ & 0.99 & $0.70-1.41$ & 0.97 \\
\hline $60-69$ & 1.10 & $0.93-1.30$ & 0.26 \\
\hline $70+$ & 0.99 & $0.75-1.30$ & 0.94 \\
\hline \multicolumn{4}{|l|}{ Race (Reference: Caucasian) } \\
\hline African American & 1.92 & $1.65-2.23$ & $<0.001$ \\
\hline Other & 1.15 & $0.59-2.19$ & 0.68 \\
\hline \multicolumn{3}{|c|}{ Race Age of first shave (Race reference: Caucasian, Age of first shave reference: $<16$ years) } & 0.53 \\
\hline African American * $16-18$ years & 0.82 & $0.44-1.52$ & 0.53 \\
\hline Other * $16-18$ years & 8.34 & $0.52-31.0$ & 0.97 \\
\hline African American * $>18$ years & 0.82 & $0.41-1.64$ & 0.57 \\
\hline Other $^{*}>18$ years & 2.04 & $0.59-7.32$ & 0.97 \\
\hline \multicolumn{3}{|c|}{ Race*Height (Race reference: Caucasian, Height reference: $<175 \mathrm{~cm}$ ) } & 0.38 \\
\hline African American * $175-180 \mathrm{~cm}$ & 1.10 & $0.73-1.66$ & 0.66 \\
\hline Other * $175-180 \mathrm{~cm}$ & 0.93 & $0.15-5.08$ & 0.94 \\
\hline African American * $>180 \mathrm{~cm}$ & 1.01 & $0.71-1.46$ & 0.94 \\
\hline Other ${ }^{*}>180 \mathrm{~cm}$ & 2.00 & $0.65-6.61$ & 0.40 \\
\hline \multicolumn{4}{|l|}{ PSA (Reference: 0-4 ng/ml) } \\
\hline $4-10$ & 2.52 & $2.04-3.12$ & $<0.001$ \\
\hline $10-20$ & 2.69 & $2.03-3.57$ & $<0.001$ \\
\hline $20+$ & 7.85 & $5.21-12.06$ & $<0.001$ \\
\hline \multicolumn{4}{|l|}{ Free PSA (Reference: <10\%) } \\
\hline $10-20 \%$ & 0.41 & $0.26-0.64$ & $<0.001$ \\
\hline$>20 \%$ & 0.22 & $0.13-0.37$ & $<0.001$ \\
\hline Clinical stage $(\geq T 2$ versus $\leq T 1)$ & 0.82 & $0.68-0.99$ & 0.040 \\
\hline \multicolumn{4}{|l|}{ TRUS Volume (Reference: <40 cc) } \\
\hline $40-80 \mathrm{cc}$ & 0.48 & $0.40-0.56$ & $<0.001$ \\
\hline$>80$ & 0.22 & $0.16-0.30$ & $<0.001$ \\
\hline \multicolumn{4}{|l|}{ BMI (Reference: $18.5-24.9 \mathrm{~kg} / \mathrm{m}^{2}$ ) } \\
\hline$<18.5$ & 0.98 & $0.50-1.91$ & 0.95 \\
\hline $25-29.9$ & 0.94 & $0.76-1.15$ & 0.55 \\
\hline $30-34.9$ & 0.91 & $0.72-1.14$ & 0.41 \\
\hline$>35$ & 1.07 & $0.82-1.38$ & 0.63 \\
\hline Family history (yes vs. no) & 1.54 & $1.16-2.07$ & $<0.001$ \\
\hline
\end{tabular}

BMI, body mass index; $\mathrm{Cl}$, confidence interval; OR, odds ratio; PSA, prostate-specific antigen; TRUS, transrectal ultrasound. 
Table S10 Predictors of presence of high grade cancer on prostate biopsy (Univariable) in the subcohort of patients with no missing data ( $\mathrm{n}=1,176$ )

\begin{tabular}{|c|c|c|c|}
\hline Variable & OR & $95 \% \mathrm{Cl}$ & P-value \\
\hline \multicolumn{4}{|c|}{ Age of first shave (Reference: $<16$ years) } \\
\hline $16-18$ & 1.02 & $0.65-1.63$ & 0.95 \\
\hline$>18$ & 0.74 & $0.43-1.28$ & 0.29 \\
\hline \multicolumn{4}{|l|}{ Height (Reference: <175 cm) } \\
\hline $175-180$ & 0.84 & $0.61-1.15$ & 0.28 \\
\hline$>180$ & 0.91 & $0.72-1.24$ & 0.68 \\
\hline \multicolumn{4}{|l|}{ Age at biopsy (Reference: 50-59) } \\
\hline$<50$ & 0.62 & $0.30-1.15$ & 0.16 \\
\hline $60-69$ & 1.03 & $0.79-1.34$ & 0.84 \\
\hline $70+$ & 2.30 & $1.59-3.28$ & $<0.001$ \\
\hline \multicolumn{4}{|l|}{ Race (Reference: Caucasian) } \\
\hline African American & 1.69 & $1.33-2.14$ & $<0.001$ \\
\hline Other & 0.28 & $0.016-1.31$ & 0.21 \\
\hline \multicolumn{3}{|c|}{ Race ${ }^{\star}$ Age of first shave (Race reference: Caucasian, Age of first shave reference: $<16$ years) } & 0.29 \\
\hline African American * $16-18$ years & 0.61 & $0.21-1.83$ & 0.30 \\
\hline Other * $16-18$ years & 0.77 & $0.32-2.35$ & 0.82 \\
\hline African American * $>18$ years & 0.93 & $0.59-1.76$ & 0.90 \\
\hline Other $^{*}>18$ years & 1.29 & $0.56-2.98$ & 0.88 \\
\hline \multicolumn{3}{|c|}{ Race*Height (Race reference: Caucasian, Height reference: $<175 \mathrm{~cm}$ ) } & 0.82 \\
\hline African American * $175-180 \mathrm{~cm}$ & 1.01 & $0.52-1.95$ & 0.79 \\
\hline Other * $175-180 \mathrm{~cm}$ & 0.39 & $0.09-1.73$ & 0.89 \\
\hline African American * $>180 \mathrm{~cm}$ & 1.03 & $0.59-1.82$ & 0.72 \\
\hline Other ${ }^{*}>180 \mathrm{~cm}$ & 0.37 & $0.12-1.45$ & 0.98 \\
\hline \multicolumn{4}{|l|}{ PSA (Reference: 0-4 ng/ml) } \\
\hline $4-10$ & 2.57 & $1.65-4.20$ & $<0.001$ \\
\hline $10-20$ & 3.92 & $2.34-6.78$ & $<0.001$ \\
\hline $20+$ & 19.48 & $11.55-34.11$ & $<0.001$ \\
\hline \multicolumn{4}{|l|}{ Free PSA (Reference: <10\%) } \\
\hline $10-20 \%$ & 0.27 & $0.15-0.50$ & $<0.001$ \\
\hline$>20 \%$ & 0.18 & $0.064-0.41$ & $<0.001$ \\
\hline Clinical stage $(\geq \mathrm{T} 2$ versus $\leq \mathrm{T} 1)$ & 1.49 & $0.10-0.68$ & 0.0071 \\
\hline \multicolumn{4}{|l|}{ TRUS Volume (Reference: <40 cc) } \\
\hline $40-80 \mathrm{cc}$ & 0.54 & $0.41-0.70$ & $<0.001$ \\
\hline$>80$ & 0.22 & $0.097-0.42$ & $<0.001$ \\
\hline \multicolumn{4}{|l|}{ BMI (Reference: $18.5-24.9$ kg/m²) } \\
\hline$<18.5$ & 0.99 & $0.33-2.41$ & 0.98 \\
\hline $25-29.9$ & 0.63 & $0.45-0.87$ & 0.0043 \\
\hline $30-34.9$ & 0.82 & $0.59-1.16$ & 0.26 \\
\hline$>35$ & 1.06 & $0.72-1.53$ & 0.78 \\
\hline Family history (yes vs. no) & 1.10 & $0.76-1.57$ & 0.62 \\
\hline
\end{tabular}

BMI, body mass index; $\mathrm{Cl}$, confidence interval; OR, odds ratio; PSA, prostate-specific antigen; TRUS, transrectal ultrasound. 
Table S11 Predictors of presence of high volume cancer on prostate biopsy (univariable) in the subcohort of patients with no missing data ( $\mathrm{n}=1,176)$

\begin{tabular}{|c|c|c|c|}
\hline Variable & OR & $95 \% \mathrm{Cl}$ & P-value \\
\hline \multicolumn{4}{|c|}{ Age of first shave (Reference: $<16$ years) } \\
\hline $16-18$ & 1.08 & $0.72-1.66$ & 0.71 \\
\hline$>18$ & 1.03 & $0.64-1.66$ & 0.90 \\
\hline \multicolumn{4}{|l|}{ Height (Reference: <175 cm) } \\
\hline $175-180$ & 1.00 & $0.76-1.30$ & 0.99 \\
\hline$>180$ & 0.98 & $0.78-1.25$ & 0.89 \\
\hline \multicolumn{4}{|l|}{ Age at biopsy (Reference: 50-59) } \\
\hline$<50$ & 0.65 & $0.38-1.07$ & 0.11 \\
\hline $60-69$ & 0.90 & $0.73-1.12$ & 0.35 \\
\hline $70+$ & 1.51 & $1.08-2.08$ & 0.014 \\
\hline \multicolumn{4}{|l|}{ Race (Reference: Caucasian) } \\
\hline African American & 1.53 & $1.26-1.89$ & $<0.001$ \\
\hline Other & 1.39 & $0.56-3.03$ & 0.44 \\
\hline \multicolumn{3}{|c|}{ Race ${ }^{\star}$ Age of first shave (Race reference: Caucasian, Age of first shave reference: $<16$ years) } & 0.35 \\
\hline African American * $16-18$ years & 0.64 & $0.27-1.47$ & 0.29 \\
\hline Other * $16-18$ years & 2.87 & $0.73-5.12$ & 0.98 \\
\hline African American * $>18$ years & 0.92 & $0.35-2.39$ & 0.86 \\
\hline Other $^{*}>18$ years & 2.46 & $0.51-4.12$ & 0.98 \\
\hline \multicolumn{3}{|c|}{ Race*Height (Race reference: Caucasian, Height reference: $<175 \mathrm{~cm}$ ) } & 0.41 \\
\hline African American * $175-180 \mathrm{~cm}$ & 1.27 & $0.73-2.19$ & 0.39 \\
\hline Other * $175-180 \mathrm{~cm}$ & 2.13 & $0.23-6.84$ & 0.47 \\
\hline African American * $>180 \mathrm{~cm}$ & 1.03 & $0.64-1.67$ & 0.90 \\
\hline Other ${ }^{*}>180 \mathrm{~cm}$ & 1.98 & $0.22-15.6$ & 0.51 \\
\hline \multicolumn{4}{|l|}{ PSA (Reference: 0-4 ng/ml) } \\
\hline $4-10$ & 2.57 & $1.80-3.76$ & $<0.001$ \\
\hline $10-20$ & 3.49 & $2.28-5.42$ & $<0.001$ \\
\hline $20+$ & 18.68 & $11.76-30.28$ & $<0.001$ \\
\hline \multicolumn{4}{|l|}{ Free PSA (Reference: <10\%) } \\
\hline $10-20 \%$ & 0.47 & $0.28-0.76$ & 0.002 \\
\hline$>20 \%$ & 0.23 & $0.11-0.46$ & $<0.001$ \\
\hline Clinical stage $(\geq \mathrm{T} 2$ versus $\leq \mathrm{T} 1)$ & 1.50 & $1.17-1.91$ & 0.001 \\
\hline \multicolumn{4}{|l|}{ TRUS Volume (Reference: <40 cc) } \\
\hline $40-80 \mathrm{cc}$ & 0.44 & $0.35-0.56$ & $<0.001$ \\
\hline$>80$ & 0.09 & $0.037-0.20$ & $<0.001$ \\
\hline \multicolumn{4}{|l|}{ BMI (Reference: $18.5-24.9 \mathrm{~kg} / \mathrm{m}^{2}$ ) } \\
\hline$<18.5$ & 0.71 & $0.26-1.62$ & 0.45 \\
\hline $25-29.9$ & 0.65 & $0.50-0.84$ & 0.001 \\
\hline $30-34.9$ & 0.74 & $0.55-0.98$ & 0.039 \\
\hline$>35$ & 0.78 & $0.56-1.09$ & 0.15 \\
\hline Family history (yes vs. no) & 1.45 & $1.07-1.95$ & 0.016 \\
\hline
\end{tabular}

BMI, body mass index; $\mathrm{Cl}$, confidence interval; OR, odds ratio; PSA, prostate-specific antigen; TRUS, transrectal ultrasound. 
Table S12 Association between patient characteristics and prostate volume on ultrasound at biopsy (univariable) in the subcohort of patients with no missing data $(\mathrm{n}=1,176)$

\begin{tabular}{|c|c|c|c|}
\hline Variable & OR & $95 \% \mathrm{Cl}$ & $P$ value \\
\hline \multicolumn{4}{|c|}{ Age of first shave (Reference: $<16$ years) } \\
\hline $16-18$ & 0.99 & $0.91-1.07$ & 0.73 \\
\hline$>18$ & 0.99 & $0.91-1.09$ & 0.90 \\
\hline \multicolumn{4}{|l|}{ Height (Reference: $<175 \mathrm{~cm}$ ) } \\
\hline $175-180$ & 1.07 & $1.01-1.13$ & 0.024 \\
\hline$>180$ & 1.10 & $1.04-1.15$ & $<0.001$ \\
\hline \multicolumn{4}{|l|}{ Age at biopsy (Reference: 50-59) } \\
\hline$<50$ & 1.26 & $1.15-1.39$ & $<0.001$ \\
\hline $60-69$ & 1.51 & $1.38-1.65$ & $<0.001$ \\
\hline $70+$ & 1.69 & $1.51-1.89$ & $<0.001$ \\
\hline \multicolumn{4}{|l|}{ Race (Reference: Caucasian) } \\
\hline African American & 1.03 & $0.99-1.08$ & 0.11 \\
\hline Other & 1.01 & $0.85-1.21$ & 0.93 \\
\hline \multicolumn{4}{|l|}{ PSA (Reference: 0-4 ng/ml) } \\
\hline $4-10$ & 1.18 & $1.12-12.4$ & $<0.001$ \\
\hline $10-20$ & 1.43 & $1.33-1.54$ & $<0.001$ \\
\hline $20+$ & 1.56 & $1.42-1.73$ & $<0.001$ \\
\hline \multicolumn{4}{|l|}{ Free PSA (Reference: <10\%) } \\
\hline $10-20 \%$ & 1.35 & $1.21-1.50$ & $<0.001$ \\
\hline$>20 \%$ & 1.67 & $1.48-1.90$ & $<0.001$ \\
\hline Clinical stage $(\geq \mathrm{T} 2$ versus $\leq \mathrm{T} 1)$ & 0.87 & $0.83-0.92$ & $<0.001$ \\
\hline \multicolumn{4}{|l|}{ BMI (Reference: $18.5-24.9 \mathrm{~kg} / \mathrm{m}^{2}$ ) } \\
\hline$<18.5$ & 1.22 & $1.01-1.46$ & 0.033 \\
\hline $25-29.9$ & 1.30 & $1.08-1.55$ & 0.004 \\
\hline $30-34.9$ & 1.46 & $1.21-1.74$ & $<0.001$ \\
\hline$>35$ & 1.44 & $1.19-1.72$ & $<0.001$ \\
\hline Family history (yes vs. no) & 0.99 & $0.92-1.06$ & 0.70 \\
\hline
\end{tabular}

$\mathrm{BMI}$, body mass index; $\mathrm{Cl}$, confidence interval; OR: odds ratio; PSA, prostate-specific antigen.

Table S13 Association between patient characteristics and prostate volume on ultrasound at biopsy (multivariable*) in the subcohort of patients with no missing data $(\mathrm{n}=1,176)$

\begin{tabular}{lccc}
\hline Age of first shave (categorical, reference: $<16)$ & OR & $95 \% \mathrm{Cl}$ & $\mathrm{P}$ \\
\hline $16-18$ & 1.11 & $0.89-1.39$ & 0.36 \\
$>18$ & 1.13 & $0.86-1.47$ & 0.37 \\
Height (categorical, reference: $<175 \mathrm{~cm})$ & & $0.80-1.11$ & 0.48 \\
$175-180 \mathrm{~cm}$ & 0.94 & $0.86-1.15$ & 0.96 \\
$>180 \mathrm{~cm}$ & 1.00 & & \\
\hline
\end{tabular}

${ }^{*}$ Controlling for patient age, race, prostate specific antigen, \% free prostate specific antigen, clinical stage, body mass index, family history. 